\author{
Branislava Vičar \\ Filozofska fakulteta, Maribor \\ DOI: 10.4312/SSJLK.57.29-36
}

\title{
Seksistični grafiti in njihova preoblikovanja
}

\begin{abstract}
Prispevek preučuje seksizem, kakor ga odražajo ter obenem vzdržujejo in reproducirajo grafiti na ulicah in zidovih slovenskih mest. Pojmovni okvir, v katerega umestim seksistične grafite, je koncept govora, ki rani Judith Butler. Seksistični grafiti, ki jih v zadnjem desetletju spremljamo na zidovih slovenskih ulic, so označevalec dobe neoliberalnega kapitalizma, za katero je značilno, kot za vse različice kapitalizma, da sistematično utrjuje, krepi in poglablja patriarhat. Seksizem $\checkmark$ grafitih je praviloma odkrit in neposreden, osebe zvečine seksualno objektivizira, neredko spodbuja k seksualnemu nasilju. Sočasno s pojavljanjem seksističnih grafitov, ki se vzpostavljajo kot učinek institucionalnega patriarhata na mikroravni, lahko spremljamo tudi širjenje feminističnih grafitov, ki predstavljajo odziv na seksizem v grafitih, kakor tudi na družbenopolitične strukture, ki ulični seksizem omogočajo. Besedna preigravanja, ki preoblikujejo seksistične grafite, razkrivajo, da je tudi govor, ki rani, ranljiv, tj. odprt za delegitimacijo in nevtralizacijo.
\end{abstract}

poststrukturalizem, razmerja moči, seksizem, feminizem, politični grafiti

The paper considers the sexism expressed, maintained and reproduced by graffiti on the streets and walls of Slovene towns. The conceptual framework used here for discussing sexist graffiti is Judith Baker's concept of injurious speech. The sexist graffiti that has appeared in recent decades on Slovene streets are a marker of the period of neoliberal capitalism, which like all variants of capitalism, is characterised by the fact that it systematically reinforces, strengthens and deepens patriarchy. Sexism in graffiti is usually open and direct, most sexually objectifies the subject, frequently it encourages sexual violence. Alongside this sexual graffiti, which at the micro-level appears as a result of institutional patriarchy, we can also observe a widening of feminist graffiti, which represents a response to sexism in graffiti, as well as to the socio-political structures that facilitate street sexism. The word play involved in sexist graffiti reveals also that injurious speech is also vulnerable, i.e. open to deligitimisation and neutralisation.

post-structuralism, power relations, sexism, feminism, political graffiti

\section{Govor, ki rani}

$\checkmark$ prispevku ${ }^{1}$ preučujem seksizem, kakor ga odražajo ter obenem vzdržujejo in reproducirajo grafiti na ulicah in zidovih slovenskih mest. ${ }^{2}$ Pojmovni okvir, v katerega umestim seksistične grafite, je koncept govora, ki rani Judith Butler (1997). Butler je koncept razvila v delu Excitable Speech (1997) ter ga vpela v poststrukturalistični teoretski okvir in poststrukturalistično pojmovanje subjektivnosti. Slednje se nanaša na fluidne mreže subjektnega pozicioniranja (tj. načinov bivanja), subjektivnost kot mesto boja ter subjektivnost kot spreminjajočo se v času (Baxter 2016: 37-38). Pri tem je treba poudariti, da posameznice in posamezniki niso umeščeni zgolj na eno družbeno pozicijo, ampak se konstituirajo $v$ prepletu subjektivnosti glede na razmerja družbene moči (to pomeni, da enkrat zasedajo privilegirano in drugič deprivilegirano družbeno pozicijo).

1 Delo je nastalo v okviru raziskovalnega programa "Slovenski jezik - bazične, kontrastivne in aplikativne raziskave« (P60215), ki ga financira Javna agencija za raziskovalno dejavnost Republike Slovenije.

2 Gradivni vzorec predstavljajo grafiti iz nabora, ki ga je leta 2013 v okviru projekta DekontRaminacija začelo pripravljati Društvo Appareo, trenutno pa se dopolnjuje pod okriljem Društva Parada ponosa. 
Butler (1997) razvije občutljivost za dejstvo, da se ljudje vsaj do določene mere konstituirajo z jezikom. Kot izhaja iz razprave, potenciala določenih jezikovnih oblik, da ranijo, ne bi zaznale, zaznali kot takega, če bi bile jezikovne strukture družbeno nevtralne: „Bi nas jezik lahko ranil, če ne bi bili v nekem smislu jezikovna bitja, tj. bitja, ki potrebujejo jezik, da obstajajo? Je naša občutljivost za jezik posledica tega, da se konstituiramo z jezikovnimi izrazi? «(Butler 1997: 1-2) Butler koncept govora, ki rani, izgradi na asociativni povezavi s telesno poškodbo (rano), da bi ponazorila, da »jezik lahko deluje na načine, ki vzporejajo povzročanje fizične bolečine in žaljivko« (prav tam: 4). Avtorica se ukvarja z vprašanjem, od kod izhaja moč določenih jezikovnih oblik, da ranijo, in pojasnjuje, da so ta potencial pridobile v svojih diskurzivnih zgodovinah: "llokucijsko govorno dejanje izvede dejanje $v$ trenutku izrekanja, a če upoštevamo razsežnost, do katere je trenutek ritualiziran, to ni nikoli zgolj posamičen trenutek. Trenutek v ritualu je zgoščena zgodovinskost [...], učinek preteklih in prihodnjih priklicev, ki konstituirajo izrek in mu uhajajo. (prav tam: 3) Moč govora, da rani, po Butler torej ne izhaja iz izrečenih/zapisanih besed kot takih, ampak se ta potencial akumulira skozi zapuščino podobnih načinov konstituiranja subjekta v diskurzivni zgodovini $^{3}$ oziroma povedano z besedami Butler skozi »zapuščine rabe, ki omejujejo in omogočajo govor govorke, govorca« (prav tam: 27). Moč govora, da rani, je tesno prepletena z družbenimi umeščenostmi, ki se opirajo na zgodovinskost razmerij družbene moči. Govor, ki rani, ponavlja pogoje družbenih neenakosti, tj. "opre se na takšne pogoje družbenih umeščenosti, ki so grožnjo, vsebovano v govoru, ki poškoduje, že realizirali« (Perger, Mencin Čeplak 2017: 219). Iz tega izhaja, da govor, ki rani, ne samo deluje na naslovnico oziroma naslovnika, temveč tudi utrjuje in reproducira podrejenost družbene skupine, ki ji naslovnica oziroma naslovnik pripada. Če sklenem, govor, ki rani, ne odslikava zgolj odnosov prevlade, ampak sodeluje pri njihovi reprodukciji, s tem pa postane sredstvo, s katerim se hierarhična družbena strukturiranost ponovno vzpostavlja (Butler 1997: 18). Obravnava vprašanja, kako diskurz prispeva k neenakim razmerjem družbene moči med udeleženkami in udeleženci diskurza ter posledično k družbeni marginalizaciji in diskriminaciji, povezuje poststrukturalistične pristope s kritično diskurzivno analizo, kar na več mestih izpostavi tudi Vojko Gorjanc (npr. 2015).

\section{Politični grafiti in njihova apropriacija}

V najširšem smislu lahko grafite opredelimo kot vidne vpise v javni prostor, tj. napisana, izrisana, naslikana, vrezana, vpraskana sporočila na javno dostopni površini (npr. Blume 1985; Klingman, Shalev 2001: 495). Na javnih mestih, kot so zidovi, mostovi, podvozi, avtobusne in železniške postaje, semaforji, prometni znaki, klopi, javna stranišča, drogovi, pločniki idr. (Velikonja 2013: 117; Waldner, Dobratz 2013: 377-378), se grafiti uveljavljajo kot »Označevalec določenega zgodovinskega obdobja (Hardt v: Velikonja 2013: 117). Grafiti so zmeraj večkodni; tudi če so sestavljeni samo iz besed, njihovo sporočilo tvori kombinacija več semiotskih kodov, kot so jezik, tipografija in barve, del sporočila je lahko tudi podlaga oziroma okolje, v katerega so grafiti umeščeni. Lahko nastanejo z enkratnim ali več zaporednimi dejanji v daljšem časovnem obdobju,

3 Gorjanc (2005: 199) pri obravnavi žaljivosti slovarskega diskurza npr. ugotavlja, da se žaljivost opira na predsodke do določene družbene skupine in z njimi povezane stereotipe, ki se lahko fosilizirajo v jezikovnih izrazih. 
lahko so delo skupine ali posameznice oziroma posameznika (Waldner, Dobratz 2013: 381). Ključna za razumevanje grafitov je njihova neinstitucionalna umestitev na ulico (Velikonja 2008: 27). Razmerje med grafiti in javnim prostorom je pri tem dialoško; grafiti soustvarjajo javni prostor, hkrati pa javni prostor sooblikuje grafite. Velik del grafitov nastaja nezakonito, tj. predstavlja nedovoljeni del ulične vizualne ustvarjalnosti (prav tam), zato so podvrženi odstranjevanju (s strani mestnih oblasti) in so posledično neobstojni. Grafiti so diskurzivno gibki in omogočajo interakcijo med posameznicami in posamezniki oziroma različnimi družbenimi skupinami. Lahko se preoblikujejo z alternativnimi sporočili in na ta način postanejo zidovi prostor družbenih bojev (Klingman, Shalev 2001; Perger, Mencin Čeplak 2017). Družbeni konflikti torej »najdejo svoje raznolike izrise ne le na ulicah, temveč tudi na njihovih stenah« (Perger 2019). Čeprav živimo v digitalni dobi, ki omogoča, da se ljudje na družbenih omrežjih izražajo svobodno, anonimno in brez omejitev, ljudje vztrajajo pri pisanju na zidove, torej grafiti kljub razvoju novih medijev še nadalje izpolnjujejo svoje specifične družbene funkcije (Debras 2019: 5).

Grafiti lahko konstituirajo eksplicitno politični diskurz, ki izziva odnose družbene moči, vpisane $v$ različne družbene institucije in kulturne prakse. Ker so umeščeni v lokalni prostor, se uresničujejo na mikronivoju političnega sodelovanja in aktivizma, a diskurzivno se umeščajo nasproti dominantnim diskurzom in institucijam makronivoja. Politični grafiti imajo potencial za ostritev družbene in politične zavesti (Waldner, Dobratz 2013: 384). Navadno izpostavljajo družbene strukture in družbene hierarhije in so nujno protihegemonski (prav tam: 381). Kot oblika neinstitucionaliziranega političnega sodelovanja izzivajo normativni družbeni red in izražajo potrebo po družbeni in politični spremembi, pogosto s kratkimi, jedrnatimi in udarnimi slogani (Perger 2019; Velikonja 2008: 32). Camille Debras (2019) prepoznava tri temeljne funkcije, ki jih izpolnjujejo politični grafiti: upor proti zatiranju; interaktivna funkcija: vzpostavljanje dialoga (z lokalnimi in nacionalnimi oblastmi); legitimacija emancipacijskega gibanja z umestitvijo gibanja v širši zgodovinski, geografski in družbeno-politični kontekst, s čimer grafiti pridobijo politično moč. Politični grafit postane sredstvo marginaliziranih družbenih skupin, ki nimajo dostopa do institucionaliziranih oblik političnega sodelovanja in "prenaša marginalizirana sporočila na širše področje javnega diskurza" (Hanauer v: Debras 2019: 5). Ali kot zapiše Mitja Velikonja (2008: 32): "sprej je orožje tistih, ki nimajo dostopa do drugih medijev izražanja, ki so v notoričnem komunikacijskem in političnem deficitu, definitivno na oni strani dominantnih diskurzov. "Vsebina političnih grafitov kot vidno vzpostavlja to, kar je v obstoječih razmerjih družbene moči nevidno ali vzpostavljeno kot manj legitimno, celo nelegitimno (Perger 2019). Politične grafite spodbuja prepričanje, da institucionalizirane politične prakse ne bodo prinesle želene spremembe (Waldner, Dobratz 2013: 387), in s tem povezana potreba po družbenem organiziranju, zato grafiti pogosto pozivajo k vzpostavitvi oziroma krepitvi in širitvi emancipacijskih gibanj. Kot zapiše Tea Hvala, postanejo grafiti, če jih beremo vzporedno z aktualnim političnim dogajanjem, "najbolj dostopno glasilo upora (Hvala 2008: 158).

Mitja Velikonja (2008) in Nina Perger (2019) opozarjata, da politične grafite pogosto apropriirajo posameznice in posamezniki ter družbene skupine z interesi po ohranitvi obstoječega družbenega reda, vključno z njegovimi neenakostmi. Del ulic in zidov zavzemajo grafiti, ki jih ustvarjajo in podpirajo "dominantne sile v družbi« (Velikonja 2008: 31), tj. prav tiste družbene strukture, k odpravi katerih pozivajo politični grafiti. Jezik zidov tako razpira številna sporočila, ki kot nelegitimne in ne- 
zaželene vzpostavljajo marginalizirane družbene skupine (glede na spol, seksualnost, nacionalnost idr.) ali pa načrtno blatijo pripadnice in pripadnike nasprotne politične opcije, tj. politične levice. Diskriminacijska sporočila, usmerjena proti ženskam, LGBTQ+ skupnosti, Rominjam in Romom, migrantkam in migrantom idr., pogosto vključujejo pozive k nasilju. Kot poudarja Velikonja (2008: 30), skrajnice in skrajneži s temi sporočili samo eksplicitno izrazijo poteze dominantnega diskurza, ki je vgrajen v obstoječe institucionalne družbene in politične strukture, tako nacionalne kot nadnacionalne; razbiramo ga na primer iz parlamentarnih debat, časopisnih uvodnikov, zakonodaje idr. Po Perger (2019) povzemam opredelitev dvojne vloge političnih grafitov. Grafiti na eni strani predstavljajo medij marginaliziranih družbenih skupin, ki opozarja na zatiranje ter poziva k emancipaciji in družbeni pravičnosti, na drugi strani pa medij skrajnih družbenih skupin, ki vzdržuje in krepi v družbi že prevladujoče prisoten diskurz izključevanja in diskriminacije. ${ }^{4}$

\section{Seksizem z zidov}

Seksistični grafiti, ki jih v zadnjem desetletju spremljamo na zidovih slovenskih ulic, so označevalec dobe neoliberalnega kapitalizma, za katero je značilno, kot za vse različice kapitalizma, da sistematično utrjuje, krepi in poglablja patriarhat (Cooke 2006: 137). Kot pojasnjuje Lilijana Burcar (2015: 5), je institucionalni patriarhat ena od strukturnih značilnosti kapitalističnega sistema ne glede na njegovo pojavno obliko. Kapitalizem in patriarhat torej nista ločena ali le naključno prekrivna sistema, ampak je vgrajevanje institucionalnega patriarhata $v$ temelje kapitalističnih držav neposredno povezano z akumulacijo zasebnega kapitala. Zato ni naključje, da se na seksistično vsebino grafitov veže obračunavanje s politično levico, kot je v grafitu POSILIMO LEVIČARKE. Seksualna objektivizacija in poziv $\mathrm{k}$ seksualnemu nasilju uokvirjata spopad $\mathrm{z}$ levim političnim polom, ta pa se vpenja v kontinuiteto izražanja političnih stališč, ki jih lahko spremljamo v parlamentarnih debatah, na družbenih omrežjih ter v drugih političnih, medijskih in kulturnih diskurzih. Če uporabim besede Velikonje (2013), gre pri tovrstnih grafitih za nadaljevanje politike dominantnih institucij, zgolj z drugimi sredstvi (in na odkrito nasilen in grob način). Na to, da gre za sistematično in politično usmerjeno grafitiranje, kaže tudi dejstvo, da se je navedeni grafit pojavil na več mestih. Sporočilo grafita je bilo kasneje nevtralizirano oziroma subvertirano z variantnimi preoblikovanji, čemur se natančneje posvečam v naslednjem poglavju.

Ulično izražen seksizem je praviloma odkrit in neposreden, v veliko primerih vključuje žaljive izraze za ženske, ki so seksualizirani, kot je na primer kurba v grafitu PIJANA KURBA. Čeprav se asimetrična razmerja družbene moči nenehno reproducirajo $z$ jezikovnimi praksami $v$ njihovi utečenosti (na primer raba moškega slovničnega spola kot generičnega), kar je še posebej značilno za jezike s slovničnim spolnim sistemom, pa se tovrstni primeri odkritega seksizma $v$ javni sferi ne dopuščajo (Mills 2008: 35). ${ }^{5}$ Predpostavimo lahko, da posamezniki svoja sporočila izražajo z grafiti, ker je to medij, ki jim omogoča najbolj neposredno in necenzurirano izražanje. Grafiti, kot so

4 Perger in Mencin Čeplak (2017) sta analizirali homo- in transfobne grafite ter ugotovili, da se sočasno z govorom, ki rani LGBTQ+ skupine, širi tudi emancipacijski govor, ki destabilizira cis- in heteronormativno družbeno strukturiranost.

5 Kljub temu pa Mills (2008: 56) opozarja, naj se ne prenaglimo v sodbah o inherentnem seksizmu posameznih besed. Kot ugotavlja na osnovi rabe seksualiziranih besed v kontekstu rapa, teh besed ni mogoče reducirati zgolj na seksistični ali homofobni pomen, saj zgodovina rabe teh besed kaže na večnivojskost pomena. 
PIJANA KURBA, JOŠKE ali PIČKE SO SAM ZA TEPST, osebe seksualno objektivizirajo in $s$ tem reproducirajo seksistično zatiranje. Seksualno objektivizacijo v analiziranih grafitih lahko strnemo v naslednje točke: 1) osebe se poimenuje in enači z deli njihovega seksualiziranega telesa; 2) ne spoštuje se telesna integriteta osebe; spodbuja se k nasilju nad njenim telesom; 3) oseba je instrumentalizirana, tj. pojmovana kot sredstvo za namene moškega; 4) zanikana je vršilskost osebe; 5) zanikana je subjektivnost osebe; to je njene izkušnje in občutja veljajo za nepomembna, torej jih ni treba upoštevati.

Med grafite s funkcijo seksualne objektivizacije se umešča tudi grafit BLACK WHORE, zapisan v angleščini. Dodatna značilnost tega grafita (glede na zgoraj navedene) je medsebojni preplet mrež zatiranja (hooks 1984: 31) oziroma medpresečnost seksizma in rasizma. Temnopolte ženske so torej zatirane na dveh nivojih; kot ženske in kot temnopolte osebe.

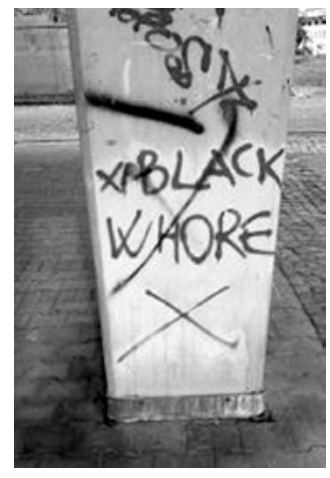

Slika 1: Black whore (arhiv: Društvo Parada ponosa)

Sočasno s pojavljanjem seksističnih grafitov, ki se vzpostavljajo kot učinek institucionalnega patriarhata na mikroravni, lahko spremljamo tudi širjenje feminističnih grafitov, ki predstavljajo odziv na seksizem v grafitih, kakor tudi na družbeno-politične strukture, ki ulični seksizem omogočajo. Slovenski feministični grafiti6 vključujejo mednarodne feministične slogane, kot so REVOLUCIJA BO FEMINISTIČNA ALI PA JE NE BO!, STOP SEKSIZMU ali grafiti, ki zahtevajo odpravo patriarhata; ti nastopajo v več jezikih in variantah: PATRIARHAT NA ODPAD!, KEIN PATRIARCHAT, SMASH THE PATRIARCHY. Grafit z angleškim sloganom ima pod sloganom upodobljeno kladivo, pod katerim se krešejo iskre, kar konotira razbijanje patriarhata, tj. osvoboditev izpod njegovih spon. S temi slogani se slovensko feministično gibanje vpenja v kontekst mednarodnih feminističnih gibanj, na ta način se legitimira kot družbeno-politično gibanje. Slogan REVOLUCIJA BO FEMINISTIČNA ALI PA JE NE BO! vključuje anarhistični simbol A, ki je vstavljen v zadnjo črko slogana, in s tem feministično revolucijo simbolno postavlja $v$ širši kontekst anarhističnega gibanja. Slogan predstavlja sestavni del feminističnih gibanj široko po svetu in čeprav posamezna gibanja ne postavljajo povsem identičnih zahtev, je vsem gibanjem skupno, da postavljajo zahtevo po vključitvi feministične perspektive v gibanje za družbeno-ekonomsko in politično spremembo ter zagovarjajo »vsesplošno feministično solidarnost kot način spremembe sveta« (Radical Socialist). Nasprotno pa grafiti, ki izražajo zahtevo po odpravi patriarhata, vpeljujejo ahistorični pogled na patriarhat, saj noben grafit ne nakazuje povezave $s$ feminističnim gibanjem, ki bi nasprotovalo "kapitalističnemu patriarhatu«, kakor je bell hooks poimenovala strukturno povezavo patriarhata in kapitalizma (hooks 2019: 6), to pa zmanjšuje politično moč grafitov.

Na splošno lahko ugotovimo, da feministični grafiti na zidovih ulic izrisujejo poteze različnih feminizmov. To najočitneje izražata dva grafita, vsebinsko vezana na 8. marec: NAMESTO ROŽE ENAKO PLAČILO in 8. MARCA - VSE NA ULICE. Prvi grafit izpostavi nasprotje med podarjanjem rož in enakim plačilom ter s tem nakaže rekontekstualizacijo 8. marca. Praznik se je namreč v osemdesetih letih 20. stoletja s postopnim vpeljevanjem kapitalistične ideologije začel ločevati od svojega

6 Analiza feminističnih grafitov $v$ Ljubljani od srede devetdesetih let 20. stoletja do leta 2008 je dostopna v Hvala 2008. 
zgodovinskega konteksta, tj. boja za žensko emancipacijo kot sestavnega dela boja proti kapitalističnemu izkoriščanju delavk in delavcev ter se je začel umeščati v kontekst praznovanja "ženskosti«. To je pomenilo, da so revolucionarno noto zamenjala obdarovanja žensk. V primerjavi s tem grafitom drugi z rabo ženske slovnične oblike pridevniškega zaimka vse $\mathrm{k}$ boju za družbeno spremembo poziva zgolj ženske; s tem vpeljuje pojmovanje o ločenih interesnih ali ženskih vprašanjih in odvrača pogled od strukturne narave spolne marginalizacije (Burcar 2015: 116-117), hkrati pa pomakne v ozadje pomembne razlike med ženskami (tj. razlike med strukturno deprivilegiranimi ženskami, kot so ženske različnih družbenih razredov, transspolne ženske itn., in privilegiranimi kategorijami žensk).

\section{Kdo se boji levičarke?}

Grafiti so medij, ki skupinam, na katere meri, omogoča hitre odzive (Perger, Mencin Čeplak 2017: 225) in politični grafiti praviloma takoj izzovejo nasprotno reakcijo (Velikonja 2013: 118). Med pripadnicami in pripadniki različnih družbenih skupin oziroma političnih opcij tako nenehno potekajo t. i. grafitarske bitke oziroma "trk[i] med sovražnimi in emancipacijskimi intervencami« (Perger 2019). Pri tem se prvotni ali predhodni grafiti bodisi fizično uničijo, npr. s prebarvanjem ali počečkanjem, bodisi se njihovo sporočilo nevtralizira in preoblikuje, in sicer z dodajanjem alternativnih sporočili na ravni samostojnih grafitov ali z minimalnimi besednimi preigravanji prvotnega grafita (Perger 2019; Velikonja 2013: 125). Možni so tudi duhoviti preobrati ali parodije na izvorna sporočila (Velikonja 2013: 125). Zidovi tako postanejo prostor družbenih bojev; iz konfrontiranj, preigravanj in izigravanj lahko »razbiramo aktualna družbena dogajanja in dinamike razmerij moči med različnimi družbenimi skupinami« (Perger 2019).

Feministična preoblikovanja opozarjajo na konkreten govor, ki rani, obenem pa na razmerja družbene moči, ki so vpisana $v$ dominantne diskurze in institucije. $V$ preoblikovanjih seksističnih grafitov se seksistično sporočilo nevtralizira in preoblikuje $v$ feministično, kot je preoblikovanje grafita PIJANA KURBA v PIJANA KURBA JE PROTI SEKSIZMU. Zid lahko postane tudi prostor boja med nasprotnicami in nasprotniki splava ter zagovornicami in zagovorniki pravice do svobodnega odločanja o rojstvu otrok, kot prikazuje slika 2. Po letu 1991 so se tudi v Sloveniji pojavila prizadevanja za izničenje ustavnega določila, ki se nanaša na pravico do svobodnega odločanja o rojstvu otrok. Ker poskusi niso uspeli, se je vprašanje pravice do umetne prekinitve nosečnosti poglobilo in preneslo v javno sfero (Burcar 2019: 447), tudi na zidove ulic. Zidove uporabljajo tako civilna gibanja in organizacije, ki želijo vplivati na javno mnenje in ga obrniti v prid prepovedi splava (prav tam), kakor feministična gibanja, ki poudarjajo pravico do svobodnega odločanja o rojstvu otrok kot temeljno človekovo pravico. Plakat na sliki 2 je del plakatne akcije krščanskega konservativnega zavoda Iskreni, s katero se organizacija vpenja v širšo kampanjo, ki meri na pravico do umetne prekinitve nosečnosti. Feministično sporočilo je dodano ob plakatu kot samostojen grafit s sloganom ŽENSKA IZBIRA, ki izpostavi repro-

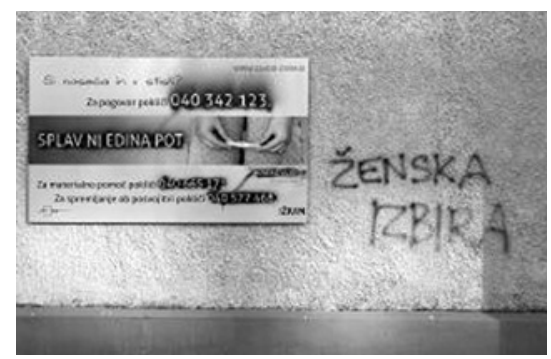

Slika 2: Ženska izbira (arhiv: Društvo Parada ponosa) 
duktivne pravice žensk in s tem vprašanje umetne prekinitve nosečnosti premesti na polje temeljnih svoboščin.

Največ "grafitarskih bitk « (tj. bitk v dopisovanjih in izbrisih) na zidovih slovenskih ulic se je odvilo $v$ zvezi $z$ že omenjenim grafitom POSILIMO LEVIČARKE. Ker prostorske omejitve ne dopuščajo predstavitve vseh preoblikovanj, naj za konec omenim dve verziji feminističnega preoblikovanja tega grafita. $V$ prvi verziji je bil grafit $z$ dodanim morfemom za- in izpisom črkovnega sklopa li preko ili preoblikovan v ZAPOSLIMO

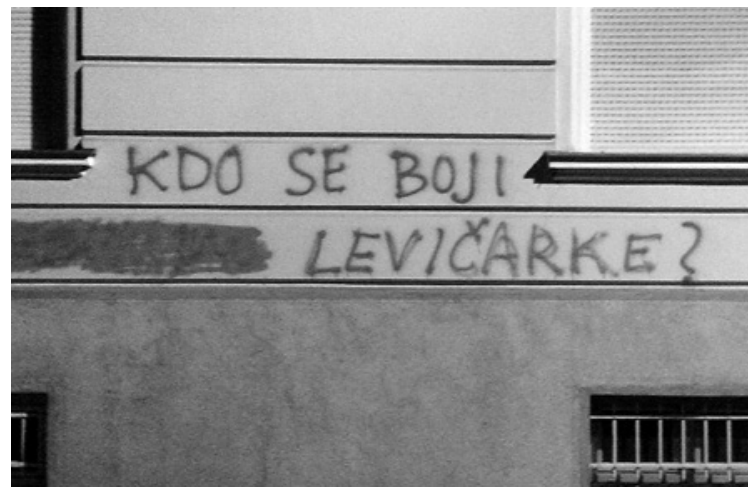

Slika 3: Kdo se boji levičarke? (arhiv: Društvo Parada ponosa) LEVIČARKE. Preoblikovanje na prvem nivoju izniči seksistično sporočilo, tj. seksualno objektivizacijo in spodbujanje seksualnega nasilja, in na drugem nivoju vpelje feministično sporočilo. Namiguje na dvoje: na prekarizacijo dela v kapitalistični družbeni ureditvi in na ekonomsko neodvisnost kot ključni cilj feminističnega gibanja.

$V$ drugi verziji je navedeni grafit s prebarvanjem glagola posilimo in dodajanjem besed postal KDO SE BOJI LEVIČARKE? Preoblikovani grafit aludira na dramo ameriškega dramatika Edwarda Albeeja Kdo se boji Virginie Woolf? Povezava med sporočilom grafita in Albeejevo dramo je občutje tesnobe in nelagodja, ki se v drami posreduje prek zavesti protagonista Georgea (navezava na tok zavesti v drami je prek reference na Virginio Woolf). Občutja negotovosti in nelagodja glede prihodnosti, ki preveva dramo, se $v$ kontekstu predelave grafita nanaša na sedanje politične strahove, ki jih za skupine, na katere grafit meri, predstavlja "pošast, ki preganja kapitalizem - pošast socializma 21. stoletja« (Lebowitz 2014: 11).

Če se na koncu povrnem h konceptu govora, ki rani, lahko sklenem, da besedna preigravanja, ki preoblikujejo seksistične grafite, oziroma grafitarski boji razkrivajo, da je tudi govor, ki rani, ranljiv, tj. odprt za delegitimacijo in nevtralizacijo, to pa izpostavlja njegov »ne-totalni značaj« (Perger 2019).

\section{Literatura}

BAXTER, Judith, 2016: Positioning Language and Identity: Poststructuralist Perspectives. Siân Preece (ur.): The Routledge Handbook of Language and Identity. London, New York: Routledge. 34-49.

BLUME, Regina, 1985: Graffiti. Teun van Dijk (ur.): Discourse and Literature. Amsterdam, Philadelphia: John Benjamins. $137-148$.

BURCAR, Lilijana, 2015: Restavracija kapitalizma: repatriarhalizacija družbe. Ljubljana: Sophia.

BURCAR, Lilijana, 2019: Kdo so čarovnice danes? Spremna beseda. Silvia Federici: Kaliban in čarovnica: ženske, telo in prvotna akumulacija. Ljubljana: Sophia.

BUTLER, Judith, 1997: Excitable Speech. London, New York: Routledge.

COOKE, Lynn Prince, 2006: Policy, Preferences, and Patriarchy. Social Politics: International Studies in Gender, State \& Society XIII/1. 117-143.

DEBRAS, Camille, 2019: Political Graffiti in May 2018 at Nanterre University. Discourse \& Society XXX/5. 1-24.

GORJANC, Vojko, 2005: Neposredno in posredno žaljiv govor v jezikovnih priročnikih: diskurz slovarjev slovenskega jezika. Družboslovne razprave XXI/48. 197-209. 
GORJANC, Vojko, 2015: Je leksikografija lahko tudi queer? Mojca Smolej (ur.): Slovnica in slovar - aktualni jezikovni opis. Obdobja 34. Ljubljana: Znanstvena založba Filozofske fakultete. http://centerslo.si/wp-content/uploads/2015/11/ 34_1-Gorjanc.pdf

HOOKS, bell, 1984: Feminist Theory: From Margin to Center. Boston: South End Press.

HOOKS, bell, 2019: Naša pozicija: razred je pomemben. Ljubljana: Sophia.

HVALA, Tea, 2008: "Enajsta šola« aktivizma: feministični in lezbični grafiti v Ljubljani. Časopis za kritiko znanosti XXXVI/ 231-232. 158-167.

KLINGMAN, Avigdor, SHALEV, Ronit, 2001: Graffiti: Voices of Israeli Youth Following the Assassination of the Prime Minister. Youth \& Society XXXII/4. 403-420.

LEBOWITZ, Michael A., 2014: Socialistična alternativa. Ljubljana: Sophia.

MILLS, Sara, 2008: Language and Sexism. Cambridge: Cambridge University Press.

MILLS, Sara, 2012: Gender Matters: Feminist Linguistic Analysis. London: Equinox Publishing.

PERGER, Nina, 2019: O dekontraminaciji, ali kako iz "LEZBIJKE NA KOLE« nastane »PRED LEZBIJKE NA KOLENA«. Misliti socialne inovacije. http://www.socialneinovacije.si/o-dekontraminaciji-ali-kako-iz-lezbijke-na-kole-nastane-pred-lezbijke-nakolena/ (dostop 2. 4. 2021)

PERGER, Nina, MENCIN ČEPLAK, Metka, 2017: Govor, ki rani, in razmerja moči: primer LGBTQ+ skupine. Časopis za kritiko znanosti XLV/268. 217-229.

Radical Socialist. http://www.radicalsocialist.in/articles/gender/376-revolution-will-be-feminist-or-it-wont-be (dostop 7. 4. 2021)

VELIKONJA, Mitja, 2008: Politika z zidov: zagate z ideologijo v grafitih in street artu. Časopis za kritiko znanosti XXXVI/ 231-232. 25-32.

VELIKONJA, Mitja, 2013: Nadaljevanje politike z drugimi sredstvi: Neofašistični grafiti in street art na Slovenskem. Časopis za kritiko znanosti XL/251. 116-126.

WALDNER, Lisa K., DOBRATZ, Betty A., 2013: Graffiti as a Form of Contentious Political Participation. Sociology Compass VII/5. 377-389. 